\title{
Usos culturales del patrimonio industrial textil en la ruralidad contemporánea de Oaxaca: el Centro de las Artes de San Agustín, Etla
}

\author{
Edith Cota Castillejos \\ Fabricio Lázaro Villaverde \\ Facultad de Arquitectura C.U. \\ Universidad Autónoma Benito Juárez de Oaxaca
}

\section{Resumen}

El conjunto fabril para la producción textil de La Soledad es una pieza arquitectónica y cultural con un nivel de influencia importante a lo largo de su historia. En este artículo se hace un recuento de su evolución, desde su diseño, el impacto cultural y social que tuvieron las fábricas en el siglo xix en México, aterrizando dichas funcionalidades con la comunidad específica de San Agustín, Oaxaca, donde se localiza el complejo; abordando los detalles técnicos de su construcción, funcionalidad e influencias (del neobarroco y góticas). Se resalta el diseño inteligente del conjunto respecto al uso del medio ambiente (la planta hidroeléctrica para abastecerse de energía, el tipo topográfico del terreno, etcétera) para favorecer la construcción de este, así como la integración de la comunidad. También se relata su decadencia por la recesión después de la revolución y, por último, su rescate como centro cultural contemporáneo bajo el nombre de Centro de las Artes de San Agustín (CASA).

Palabras clave: Patrimonio industrial textil, ruralidad contemporánea, conjunto fabril, medio ambiente, Centro de las Artes de San Agustín, San Agustín, Oaxaca.

\section{Abstract}

The factory complex for the textile production of La Soledad is an architectural and cultural piece with an important level of influence throughout its history. This article recounts its evolution from its design, the cultural and social impact that factories had in the 19th cen- 
tury in Mexico, and the specific community of San Agustín, Oaxaca, where the complex is located; addressing the technical details of its construction, functionality, and influences (neobaroque and gothic). The intelligent design of the complex is highlighted with respect to the use of the environment (the hydroelectric plant to supply energy, the topographic type of terrain, etc.) to favor its construction, as well as the integration of the community. It also describes its decadence due to the recession after the revolution and, finally, its revival as a contemporary cultural center under the name of Centro de las Artes de San Agustín (CASA).

Key words: Industrial textile heritage, contemporary rurality, factory complex, environment, Centro de las Artes de San Agustín, San Agustín, Oaxaca.

En las primeras décadas del siglo xix existió en el país una incipiente industria textil, como la pequeña fábrica de hilados y tejidos de Chito Cohetero en Puebla, o la Aurora Yucateca en Valladolid, Yucatán, de 1821 y 1826 respectivamente, iniciando con ello la importación de maquinaria y mano de obra especializada. El inicio de la llamada modernización de Oaxaca tuvo lugar desde la segunda mitad del siglo XIX, principalmente en los valles centrales y en la Sierra Norte. Es en este periodo cuando las formas de producción y reproducción cambiaron radicalmente, sobre todo por la influencia de los medios mecánicos para realizarlas, es decir, por la aplicación de la ciencia y la tecnología en los métodos de producción, para dejar a un lado los medios manuales y artesanales por los de las máquinas.

La observación y emulación de una Europa industrial, así como de un Estados Unidos tecnificado y próspero, fueron constantes para implementar cambios en el sector económico, sin considerar las diferencias históricas, económicas, sociales y fundamentalmente políticas. Una estrategia para lograr este cambio fue la fundación de fábricas, de las cuáles, el estado contó en su territorio con solo tres, de hilados y tejidos, de ahí que la fábrica adquiriera una connotación de progreso y modernidad. Se puede sintetizar este proceso de paulatina sustitución socioeconómica, que va de la grana cochinilla al textil industrial.

La formación de la oligarquía textil en Oaxaca tuvo su origen en los comerciantes que se dedicaron a los negocios industriales, siendo principalmente en el siglo XIX dos familias con sus respectivos asociados quienes fundaron las tres fábricas en Oaxaca: la familia Sáenz Trápaga-Zorilla fundó la fábrica de hilados y tejidos San José en 1873, y la fábrica La Soledad Vista Hermosa en 1883; por otro lado, la compañía Mowatt \& Grandison, fundó la fábrica de hilados y tejidos Xía, también en 1873, aprobada para la población de Zimatlán desde 1871 por el entonces gobernador Félix Díaz. ${ }^{1}$ Las fábricas de hilados y teji-

1 Velasco Rodríguez, Capitalismo y modernización en Oaxaca. La industria textil durante la Reforma y el Porfiriato, 237. 
dos San José y La Soledad se encontraron ubicadas en una zona de peculiares condiciones medioambientales propicias para su desarrollo.

El enclave rural de San José y San Agustín Vista Hermosa se encuentra localizado en la parte central del estado, colinda con los distritos de Ixtlán, al oeste; Cuicatlán y Nochixtlán al norte; y al sur con el Centro y Zaachila. Está bordeado por fértiles cañadas y afluentes de ríos, arroyos o manantiales, con actividades agrícolas, ganaderas y mineras. Con respecto al agua del río, a través del cual se produjo la energía eléctrica necesaria para las dos fábricas, existieron permisos de uso con amplios beneficios para los empresarios fabriles. Esto ocasionó conflictos con los pobladores del lugar, por tener menos derechos sobre el uso del agua. Aunado a ello, con la instalación de las fábricas, el cambio en el tipo de trabajo de la ganadería a la industria textil trajo como consecuencia, por un lado, la combinación del trabajo en el campo y en la fábrica, o su olvido, y como consecuencia de lo anterior, la modificación en la topografía del lugar por la construcción de las casas de los obreros en terrenos comunales. Sin embargo, en poco tiempo la fábrica Vista Hermosa aportó considerables sumas de dinero para la construcción de la casa municipal, el remozamiento del templo, y otras obras públicas que hicieron de San Agustín Vista Hermosa «uno de los primeros que contó con escuela, tres templos, casa y panteón municipal; además, su población se incrementaba rápidamente, a diferencia de los demás pueblos aledaños, por lo que, en unos cuantos años, San Agustín asumió la fisonomía propia de los pueblos fabriles que se originaron a partir del Porfiriato». ${ }^{2}$

\section{El conjunto fabril de La Soledad}

El conjunto de la fábrica de hilados y tejidos La Soledad en San Agustín Vista Hermosa se instaló en el desplante de la Sierra de San Felipe, sobre la falda sur del cerro conocido como Picacho, en la cañada que forma el río San Agustín o río Grande, localizado al este de la población del mismo nombre, fundada en 1583 y con antecedentes prehispánicos 300 años atrás, de ascendencia zapoteca. Esta localización es estratégica debido a la proximidad con la fuente de energía natural para su funcionamiento y para impulsar la maquinaria a través del afluente del río, convirtiéndola en energía hidroeléctrica. Al mismo tiempo, la afluente permitió el desalojo de los residuos en el proceso de producción. Pero no solo dependían de esta proximidad a la fuente de energía, también se buscó ubicar el conjunto en la red próxima, con mercados para el consumo de productos y vías de comunicación accesibles de donde abastecer la materia prima. En este caso, solo se cumplía la primera condición, estar en la proximidad del agua, y no la conexión con la ciudad de Oaxaca, pero sí una relación directa con Puebla y la Ciudad de México a través del ferrocarril, al igual que en

2 Velasco Rodríguez, Capitalismo y modernización en Oaxaca. La industria textil durante la Reforma y el Porfiriato, 315. 


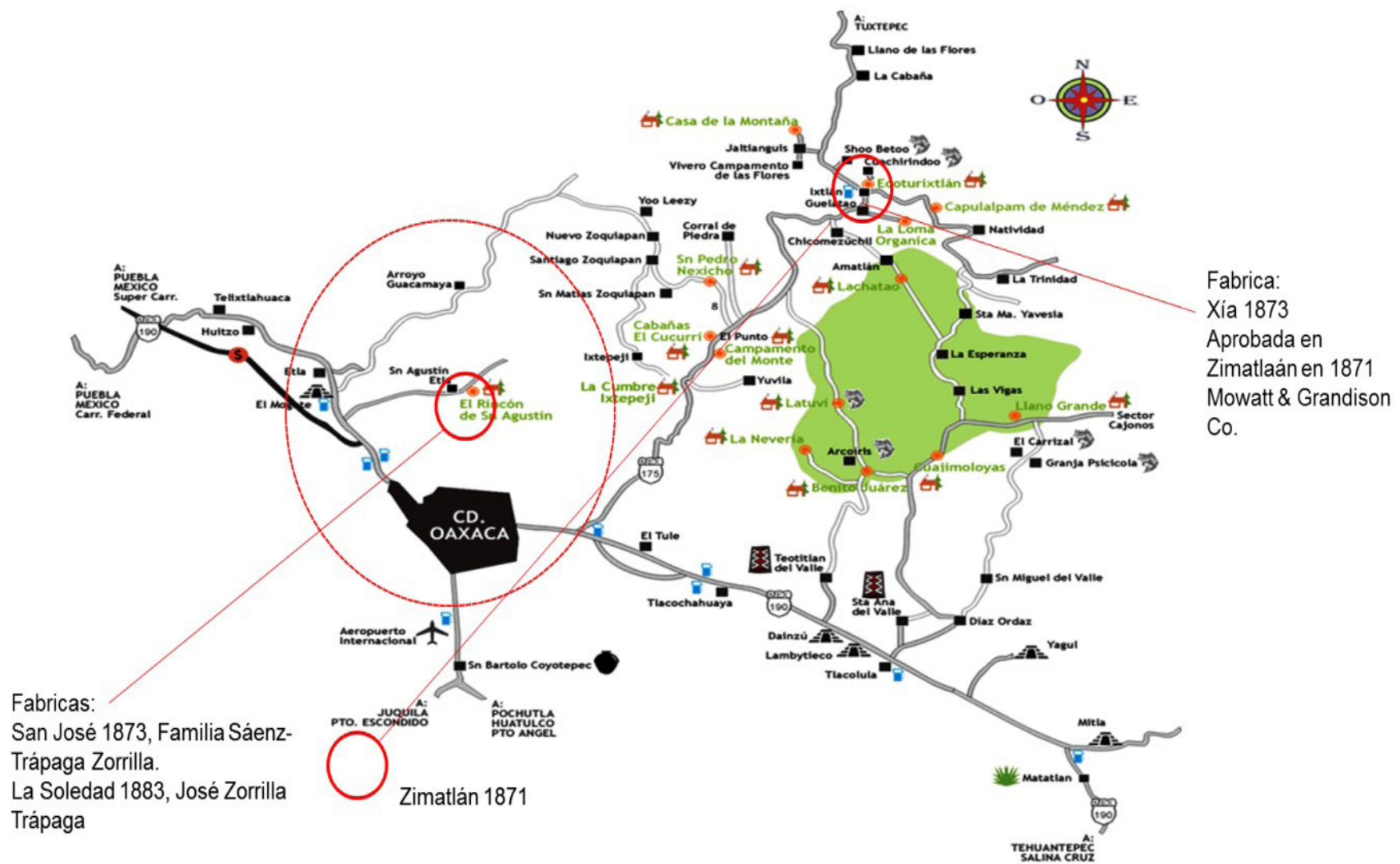

Imagen 1. Plano de ubicación de fábricas en funcionamiento a finales del siglo XIX. Elaboración de los autores. Archivo CAPUAO el cruce con Cuicatlán, con el afluente del río Santo Domingo, que conecta con Tuxtepec y el estado de Veracruz (ver imagen 1).

La fábrica La Soledad - al igual que la hidroeléctrica- fue fundada en 1883 por José Zorrilla Trápaga ${ }^{3}$ —en asociación con el empresario británico Tomas Grandison-, quien es considerado el primer inversionista de la industria textil más fuerte en Oaxaca. Diez años antes, en 1873, había fundado con sus primos, Juan Saenz y los Cajiga, la fábrica de hilados y tejidos San José. El que hayan sido inversionistas extranjeros, españoles en estos dos casos e ingleses en el caso de Xía, quienes fundaron las tres fábricas de hilados y tejidos en Oaxaca, fue habitual «del desarrollo porfirista, que estuvo basado en la inversión extranjera y demuestra el tradicionalismo de la oligarquía oaxaqueña, fundamentalmente comercial y terrateniente». ${ }^{4}$

Para lograr la construcción de la fábrica La Soledad, José Zorrilla recibió exenciones fiscales del gobernador en turno Luis Mier y Terán, con quien acordó sobre el tema de la hidroeléctrica proporcionar a partir de ella la energía necesaria para el alumbrado eléctrico en la

3 Nació en Bustancilles de Soba, España, en 1829 y murió en 1897 a la edad de 68 años, mientras ocupaba el cargo de vicecónsul de España en Oaxaca. Op. cit., 280

4 Existieron en esa misma época otras fábricas como, por ejemplo, la fábrica de calzado de Ruiz Hermanos y sobrino Sucs., fundada en 1878; la fábrica de cerveza La Mascota; dos fábricas de cigarros, La Unión y La Ópera; la fábrica de jabón La Oaxaqueña, del francés Luciano Laugier, citado en Martínez Medina y Ruiz Cervantes, «La ciudad de Oaxaca. de la independencia a los inicios del periodo posrevolucionario». En Van Doesburg (coord.), 475 años de la fundación de Oaxaca. II. Siglo XIX y XX, 64. 
ciudad de Oaxaca, ${ }^{5}$ especialmente en las oficinas públicas y algunas calles del centro, financiando la línea de alimentación entre la planta y la ciudad. Este servicio de alumbrado público urbano se consolidó «en la última década del porfiriato, durante el gobierno de Emilio Pimentel, quién también apoyo la creación de las plantas hidroeléctricas La Luz y La Soledad para dotar de alumbrado público a la ciudad de Oaxaca hasta los años treinta del siglo xx». ${ }^{6}$

El tema del agua y su relación con las distintas propiedades de tierras, molinos de agua, canales, etcétera, así como con negociaciones políticas y económicas, tiene su origen en el siglo XVI, hasta conformar ya en el siglo xıx una obra de ingeniería hidráulica relevante para el óptimo funcionamiento, primero de la fábrica de San José, y tiempo después de la fábrica La Soledad. A pesar de ello, la producción de la fábrica dependía del caudal del río y por consiguiente estaba a expensas de periodos de estiaje, razón por la cual tuvo periodos de baja producción textil.

El perfil topográfico de San Agustín Vista Hermosa es de una pendiente pronunciada, abrupta. Esta característica es más visible en las calles orientadas de norte a sur, que son de poca pendiente en la dirección este-oeste. Este tipo de topografía determinó que el asentamiento de la población utilizó para la construcción de casas un sistema de terrazas o plataformas a base de muros de contención, originando con ello su fisonomía escalonada y la presencia de niveles que conectan con escaleras exteriores e interiores. Por supuesto que, en la arquitectura del conjunto fabril, estas condiciones topográficas fueron el punto de partida para que su diseño privilegiara esta premisa del contexto natural e hiciera de ella su principal rasgo arquitectónico.

La construcción de la fábrica inició en mayo de 1883, —de acuerdo a lo señalado por la investigadora Griselle Velasco-, y estuvo a cargo del arquitecto Guillermo Desmonth ${ }^{7}$ — según la inscripción autoral de «Desmonth» en la piedra clave del templo del conjunto fabril-; sin embargo, también existen en la mapoteca de la Casa de la Ciudad cuatro proyectos para fábricas de textiles que consisten en dibujos de plantas y alzados arquitectónicos desarrollados por el ingeniero Francisco de Paula Tort Ràfols (1851-1921), de los cuales, uno de ellos tiene los siguientes datos:

Proyecto de una fábrica de mantas del Sr. Dn. José Zorrilla, ${ }^{8}$ en este sentido, Carlos Lira cita el diario la Hoja del Pueblo, del $1^{\circ}$ de diciembre de 1883 donde se dice, «los trabajos de la nueva fábrica de hilados llamada "La Soledad Vista-hermosa”, propiedad del infatigable comerciante y amigo nuestro Sr.

5 El 6 de marzo de 1883, el Diario Oficial anunciaba nuevos aparatos de luz eléctrica por el acuerdo entre los Zorrilla-Grandison y el Gobierno del estado. Citado en Velasco, op. cit., 312.

6 Martínez Medina, op.cit., 6o; Velazco Rodríguez, op. cit.

7 Quien llegó a tener un lazo político con los Saenz-Cagija-Zorrilla a través del matrimonio de una de sus hijas con un sobrino de los propietarios de la fábrica, citado en Velasco, op.cit., 327.

8 Imagen, en Martínez Medina y Ruiz Cervantes, op.cit., 61 
D. José Zorrilla continúan con gran actividad, dirigidos los del edificio por el inteligente Ing. Sr. D. Francisco Tort, y los del acueducto (obra verdaderamente atrevida y que fue nivelada por el respetado Ing. Sr. D. Damián Tort), por el Sr. Ingeniero D. Emilio Brachetti». ${ }^{9}$

De aquí se establecen dos posibles autores de la fábrica y podemos plantear la siguiente hipótesis: si Francisco Tort Ràfols mantuvo una relación personal con José Zorrilla —quien fue testigo en 1878 de su casamiento con María de la Soledad Santibáñez Maldonadoexplicaría por qué realizó una propuesta para el dueño de la fábrica La Soledad, de donde es posible inferir que esta propuesta se realizó para la mencionada fábrica sin llegar a construirse, y el ingeniero Francisco Tort Ràfols, de acuerdo a la nota del diario de 1883, fuera el encargado de construir la fábrica, mas no así el proyecto, para después él encargarse del diseño y construcción del chalet de los dueños de la fábrica La Soledad. Esta inferencia podría establecer la siguiente autoría: templo, ingeniero Guillermo Desmont; Chalet, ingeniero Francisco Tort Ràfols; Fábrica y construcción, Francisco Tort Ràfols.

Para Ramón Vargas Salguero, ${ }^{10}$ la tipología de las fábricas como iconos de la modernidad o como equipamiento para la producción y el trabajo a través de la incorporación de la máquina no tenía antecedentes en México a finales del siglo xix y principios del xx, era un género sin historia nacional. Recordemos que fue en Europa, con la llamada Revolución Industrial, donde fue necesario construir los espacios productivos. Para ello, arquitectos e ingenieros tomaron en cuenta la maquinaria como detonante dimensional de las fábricas; sin embargo, el contenido estaba en franca oposición al continente, es decir, entre forma y contenido se presentó un contraste entre tradición formal y modernidad funcional. Fue hasta las primeras décadas del siglo xx cuando se buscó una integración entre forma y función como expresión de la modernidad. Ejemplos urbano-arquitectónicos son la ciudad industrial de Tony Garnier, de 1904-1917; la fábrica de turbinas AEG, en Berlín, Alemania, de Peter Berhens, de 1908-1909; y de forma explícita, la fábrica Fagus en Alfeld an der Leine, Alemania, de Walter Gropius y Adolf Meyer, de 1911; o buscando expresividad formal con rasgos de la construcción tradicional popular, la fábrica de productos químicos en Luban, Polonia, de 1912, realizada por Hans Poelzig; así como la expresionista fábrica de sombreros en Luckenwalde, Alemania, de 1921, obra de Erich Mendelsohn.

Sin embargo, mientras en Europa la fábrica se insertaba en el contexto urbano o periférico de la ciudad receptora de la industria, lo cual garantizó el equipamiento e infraestructura, al igual que cercanía con la vivienda obrera a través de vías de comunicación, transporte, etcétera, en el caso de México, «las primeras fábricas se constituyeron como enclaves modernos en las áreas agrícolas, cuando no, en el

9 Lira Vásquez, Arquitectura y Sociedad. Oaxaca rumbo a la modernidad, 130.

10 Vargas Salguero, Historia de la Arquitectura y el Urbanismo Mexicanos, volumen III. El México Independiente, tomo II. Afirmación del nacionalismo y la Modernidad, 494. 
campo yermo». ${ }^{11}$ Estos enclaves fabriles modernos, al prosperar, por su interacción urbana ocasionaron la expansión del núcleo urbano, a través de los nuevos asentamientos, generalmente irregulares, de viviendas para trabajadores, pero esto fue posible cuando las ciudades contaron con fuentes de energía, accesos a mercados rápidos e importantes, y, sobre todo, insumos para la producción. De esta manera:

las primeras fábricas que se instalaron en el país constituyeron por lo que a su localización toca, enclaves de modernidad en localidades suburbanas o abiertamente agrarias. Las implicaciones de este hecho elemental, pero no por ello menos trascedente, le imprimieron al género industrial unos rasgos diferenciales nítidamente marcados. El programa arquitectónico general fue, por tanto, una consecuencia de las necesidades de solventar tan especiales condiciones. ${ }^{12}$

En este sentido, el conjunto fabril en San Agustín Vista Hermosa se ubicó a 17 kilómetros al norte de la ciudad capital, en un contexto rural de difícil acceso, pero con el potencial para generar la energía motriz que la fábrica necesitó. Sin duda, la interacción entre la fábrica y su preexistencia socioeconómica fue determinante para que en 1891, a solo ocho años de la construcción de la fábrica de hilados y tejidos La Soledad (1883), San Agustín fuera declarado Ayuntamien-

Imagen 2. Plano del conjunto fabril la Soledad. Fuente: Claudina López (arquitecta), responsable de la remodelación.
11 Ídem, 495.
12 Ídem, 500.

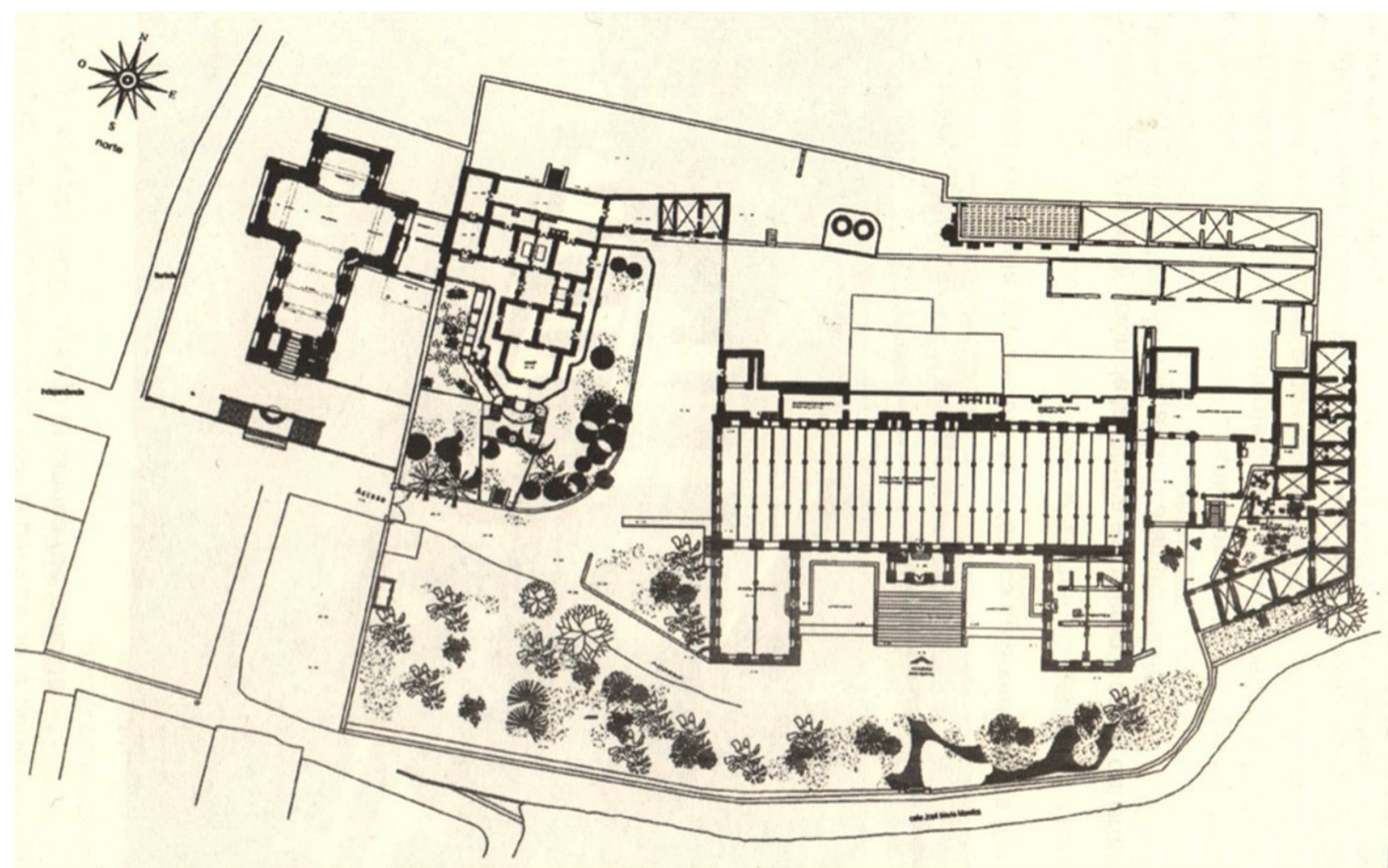


to, con los derechos y obligaciones político-administrativas que esto ocasiona.

Para el funcionamiento del conjunto fabril, la fábrica, por sus dimensiones, equipo e instalaciones, espacios relacionados directa o indirectamente, así como la cantidad de obreros que ahí laboraron, tuvo cierta complejidad el programa arquitectónico a resolver. Este conjunto, por su funcionamiento y área de un incipiente microurbanismo, pudo presentar este panorama:

al lado de las naves que alojaban la maquinaria [...] podía encontrase el cuarterío de los trabajadores con sus servicios sanitarios, la tienda de raya de ingrata memoria, en no pocas oportunidades una escuela y una capilla, esta última hasta ocupando un lugar central en el conjunto. Contrastando entre ambas zonas podía llegar a niveles de crudeza, máxima cuando, como fue el caso, la fábrica Hércules (cerca de la ciudad de Querétaro) llegó a contar con mazmorras para aplicar castigos. ${ }^{13}$

Este programa arquitectónico genérico de la fábrica tuvo sus particularidades de acuerdo al sitio donde se construyó y las condiciones socioeconómicas.

El conjunto fabril La Soledad se ubicó al noreste con respecto al centro de la población donde se encuentran el templo principal y el palacio municipal. De este centro político-religioso se inicia un camino que conduce a un asentamiento en la ladera noreste del cerro de San Agustín, y es precisamente en esta vialidad que se bifurca hacia el norte y hacia el sur donde se desplantó el conjunto fabril, es decir, ya en el asentamiento rural, el remate de esta calle fue el acceso a la fábrica de hilados y tejidos La Soledad. Desde este punto y hacia el este, el conjunto se integró por la definición de dos zonas: la de culto, integrada por la capilla, el atrio y el tianguis, y la de fábrica, claramente separada por un muro perimetral de la zona de fábrica. La planimetría fue realizada por la relación entre dos ejes, uno de desplante y otro de accesibilidad, el primero, longitudinal este-oeste, determinó la colocación y separación física de los componentes del conjunto en este orden: capilla-atrio; chalet administrativo; fábrica; cuarto de máquinas y viviendas de obreros-capataces; áreas de servicio. El eje transversal norte-sur, se convirtió en el eje principal que orienta la capilla y el chalet, ubicando sus respectivos accesos en el lado sur de cada volumen. La fábrica, cuya forma rectangular sigue al eje dominante longitudinal (este-oeste) sobre el eje transversal, dispuso en el lado sur el acceso a la fábrica y por el norte su conexión con el área de vivienda, instalaciones y servicio. Cabe señalar que la presencia de estos dos ejes es clara en la planta baja de la fábrica, donde el eje longitudinal este-oeste determina el eje de soporte de columnas, y el transversal, el eje de cubierta con las vigas metálicas (ver imagen 2).

El conjunto fabril fue desplantado bajo el criterio de realizar cortes a la ladera del cerro, con el objetivo de emplazar el funcionamiento, evitando costos de construcción excesivos, es decir, la integración

13 Ídem, 495. 
a la topografía por la intervención humana permitió practicar una serie de plataformas escalonadas desde las cuales consolidar el desplante de los edificios. De esta forma, al sistema de nivelación general lo representa la plataforma base nivelada, desde donde se practica el desplante del conjunto, a continuación, la plataforma a dos niveles en dos usos: la capilla-atrio y el chalet-jardín acceso a zona de fábrica. La tercera plataforma es la que desplanta el edificio de la fábrica, a su lado este se encuentran la cuarta plataforma del cuarto de máquinas y la casa de los capataces. Por el lado norte del edificio del chalet y la fábrica, se realizó una quinta plataforma que abarca toda la longitud del predio, donde se ubicaron las calderas, los chacuacos (o chimeneas) y las posibles casas de obreros. Hacia el lado este del conjunto fabril se practicó la construcción de una escuela primaria para los hijos de obreros, almacenes de materia prima, una posible casa habitación, el llamado molino San Diego y las caballerizas. Este conjunto fabril constaba, según el dictamen catastral de $1923,{ }^{14}$ con

fábrica, caballeriza, bodega de algodones, chalet, que constaba de 9 piezas, un cuarto de baño, dos w.c., una cocina y un jardín, templo y sacristía, tienda con subhabitación (157 m2 aproximadamente), un horno de pan, escuela para hombres (48 m2), escuela para mujeres (104 m2, 4 puertas de madera y una ventana), casas de operarios: 6 en el molino, 7 en el terreno con tienda, 2 en el costado de la misma, constando una casa de 1 pieza y 1 cocina con una superficie aproximada de 684 $\mathrm{m} 2$, además 4 grupos de 4 casas cada uno formado de una pieza y cocina con $624 \mathrm{~m} 2$, además dos casas aisladas de una sola pieza de muros de adobe y techos de teja; Molino montañes: una casa, Molino de San Diego.

Así también se hace referencia a que en el sitio donde está ubicada la tienda con su habitación, las 23 casas de operarios, el templo-sacristía y el molino de San Diego tienen un área total de 25,729.75 metros cuadrados y un valor de 251,383.14 pesos. ${ }^{15}$

La descripción de los edificios del conjunto fabril seguirá el orden de la descripción ya realizada del desplante, no tiene una secuencia cronológica porque propone un acercamiento a la experiencia del recorrido como se realizaría en esa época, y que en la actualidad permanece con un alto grado de similitud.

\section{Templo de la Virgen de La Soledad}

Pese a ser el templo la primera edificación del conjunto fabril, su posición lateral sobre el eje norte-sur la esconde ligeramente de la vista frontal de acceso por la calle, esto le confiere un cierto dinamismo y

14 Velasco, op.cit., 330.

15 De acuerdo al juicio de amparo promovido por Federico Zorrilla en contra de la Oficina de Catastro en 1923 y su posterior venta. Velasco, op.cit., 335. 


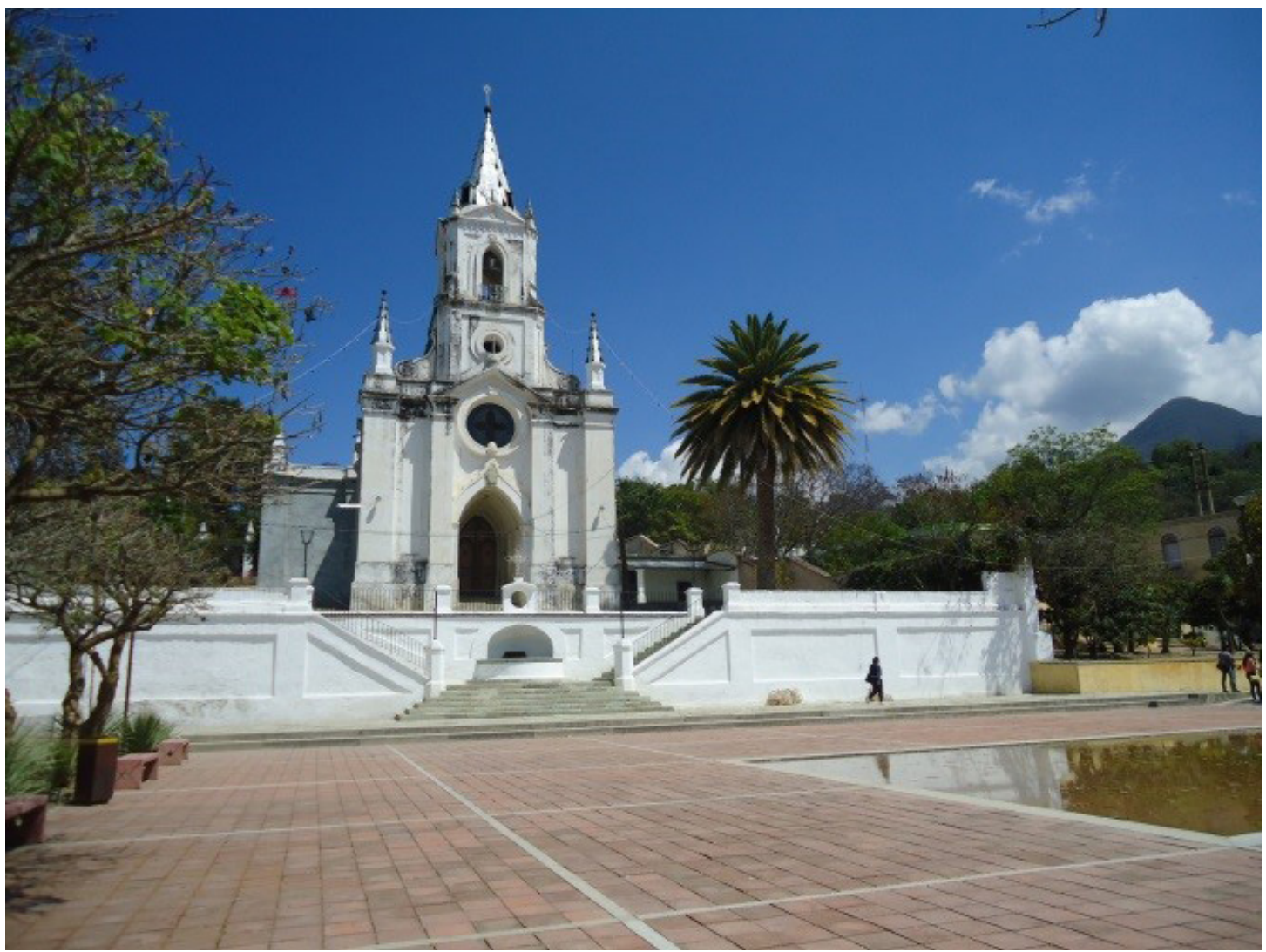

Imagen 3. Vista sur del templo de la virgen de La Soledad. Fuente: Archivo CAPUAO. fuerte protagonismo, al ser desplantada en una plataforma que se encuentra aproximadamente a 3.50 metros del nivel del llamado atrio. Para llegar a este nivel de desplante y acceso, se practicó una escalera con tres cuerpos, el primero, sobre el eje norte-sur, con una forma semicircular, culmina con una fuente y dos tramos rectos, paralelos al eje este-oeste (ver imagen 3).

La planta del templo es de cruz latina, con sus espacios característicos: acceso, sotocoro, escalera de acceso al coro y al campanario, una posible cripta de Enrique Zorrilla Tejada, nave, crucero y altar. La robustez de los muros queda manifiesta en la planta arquitectónica, así como su reforzamiento en todas las esquinas. El sistema de materiales y acabados empleados son: muros de piedra con aplanados simples; cantera en los pisos de la nave; madera en el piso; columnas de coro; lámina de zinc en la cubierta del campanario y pináculos; vidrio en las ventanas del coro y laterales; hierro colado en los barandales del atrio y del campanario; y madera en las puertas de acceso sur, este y oeste. La volumetría del templo, de clara influencia neogótica, característica de la época, acusa la verticalidad en el lado sur, donde se encuentra el acceso. Esto es conseguido por la disposición en el eje de un arco ojival para la entrada y su repetición hacia el interior, lo que produce una marcada profundidad. Sobre este vano se encuentra la ventana coral en forma circular, que se remata con un frontón triangular, a su vez, estos elementos del primer cuerpo son delimitados en cada extremo por esbeltos contrafuertes que rematan con pináculos. Sobre este cuerpo y al centro, se desarrolla la superposición de dos volúmenes achaflanados que forman el campanario, que integra un vano circular de iluminación para la escalera, así como un vano ojival donde se encuentra la campana. Este cuerpo se rema- 
ta con un frontón triangular y un chapitel de lámina de zinc. Sobre el segundo vano circular y bajo el barandal del campanario, se encuentra una placa con los siguientes datos: Noviembre 1892. G. Desmonth. Todo indica que esta es la fecha de terminación. ${ }^{16}$

\section{El chalet administrativo}

El chalet estilo francés, o bien, casa de campo de los Zorrilla, se ubica entre la capilla y la fábrica textil. La casa consta de nueve espacios, la fachada sur es la que permite el acceso (ver imagen 4). A través del cruce de un jardín, se encuentra una escalera recta con once escalones para llegar al nivel donde existe una fuente circular, pero con base octagonal. La fuente está rodeada por tres escalones que permiten llegar a otra plataforma donde encontramos una escalera de dos brazos a través de la cual se llega al nivel de la vivienda e ingresa a un espacio que funcionó como recibidor. Este último conecta con otros dos espacios: la biblioteca y el cuarto de juegos. Cada uno se vincula con lo que podría ser el comedor, y este a su vez tiene conexión con dos espacios más al fondo, que es posible que hayan sido recamaras. El comedor también tiene conexión con la cocina, pero no de manera directa, ya que para llegar a ella se tiene que salir del espacio habitable a una prolongación del mismo nivel de piso terminado de la vi-

Imagen 4. Acceso al chalet adminisrativo. Fuente: Archivo CAPUAO. vienda (esta podríamos señalarla como base de la vivienda, la cual la rodea y sobresale de los límites del muro 1.5 metros aproximadamente, en unas partes más, y en otras, la medida señalada, pero cubierta,

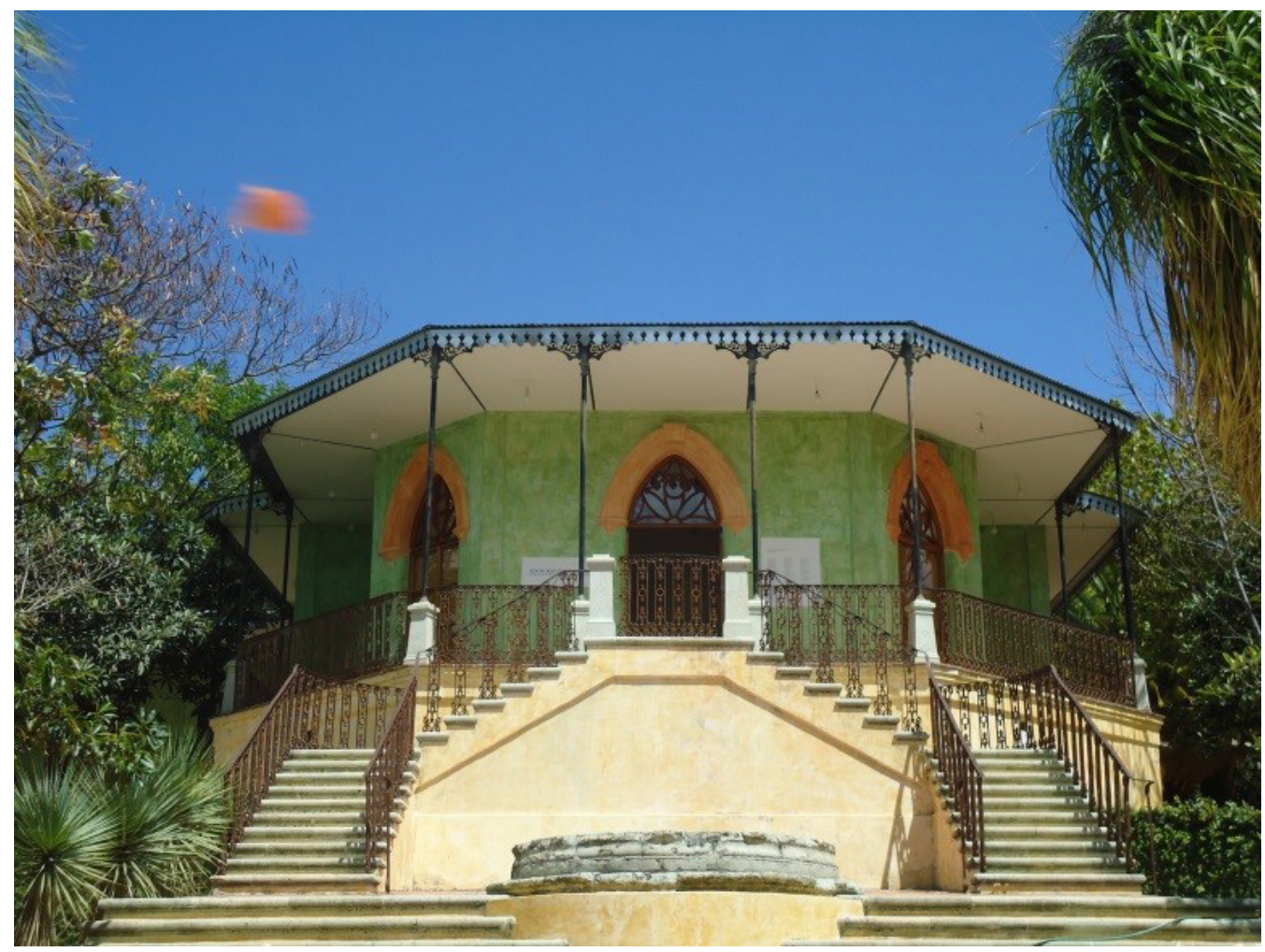

16 Para Griselle Velasco, la fecha de terminación del templo es el 21 de mayo de 1886, según la placa señalada. Op.cit., 334. 
es decir, la cubierta se proyecta para resguardar esa superficie, que también se considera como un corredor alrededor de toda la vivienda, esto permite que se conecte cocina y comedor). El espacio que se considera que pudo haber tenido la función de baño cuenta con dos puertas, una orientada hacia el este y otra hacia el norte. La primera nos conecta con un espacio que, presumiblemente, tuvo la función de vestíbulo, este tiene conexión con la cocina y con el jardín, lo que nos hace pensar que, durante el día, y para uso de las visitas, el acceso al baño era por esa puerta norte, y por la noche el acceso al baño era por la puerta este, debido a la vinculación con los espacios considerados recámaras.

El chalet es de un solo nivel, pero adquiere notoriedad volumétrica por estar emplazado en una parte alta del terreno. Está definido por una barda de poca altura cuya función es la delimitación funcional y espacial. La vivienda-chalet está rodeada por un jardín con árboles, y dadas sus características formales, como la simetría de la planta, la forma ochavada del volumen principal y el estilo de las ventanas en sus fachadas, que se encuentran en la parte media de cada muro o repartidas en tres, así como la forma vertical, con un trazo de arco gótico, permite establecer el estilo como neogótico, pero con una influencia del estilo art noveau y vitrales del mismo diseño.

El chalet, en casi la totalidad de su perímetro, hacia el oeste, sur y norte, está rodeado por un pórtico integrado por esbeltas columnas y un barandal de fierro colado, con una cubierta de lámina de zinc que genera la sombra para deambular por el exterior y también para controlar el clima del espacio interior. Los muros están hechos de adobe; las losas de un sistema de vigueta y bovedilla; y los pisos de duelas que se desplantan a más de un metro del nivel del terreno.

\section{La planta de producción}

El conjunto fabril está dominado por la escala y ubicación de la planta de producción, que se encuentra del centro de la parcela hacia el este. Ahí se realizaron las principales actividades de la fábrica: el proceso de hilatura y el de tejido, cada una de ellas en un nivel diferente. La planta baja era para los batientes, cardas, veloces, peinadoras y tróciles, así como las maquinas hiladoras, por cuyo peso y continua vibración fue indispensable contar con un piso asentado directamente sobre suelo firme. En la planta alta se realizó el tejido de productos textiles usando 180 telares, y con espacios anexos para completar el proceso (ver imagen 5 ).

La planta baja fue resuelta a partir de una forma rectangular con orientación este-oeste, sobre el eje longitudinal de desplante, practicándose los accesos en el lado sur y norte, sobre el eje transversal de accesos, estando el más importante de la fábrica en su conjunto en el lado sur, y en su interior, esta planta que tiene aproximadamente 60 metros de largo por 15 de ancho. El sistema de soporte para la cubierta en entrepiso fue resuelto a través de dos ejes de columnas de 


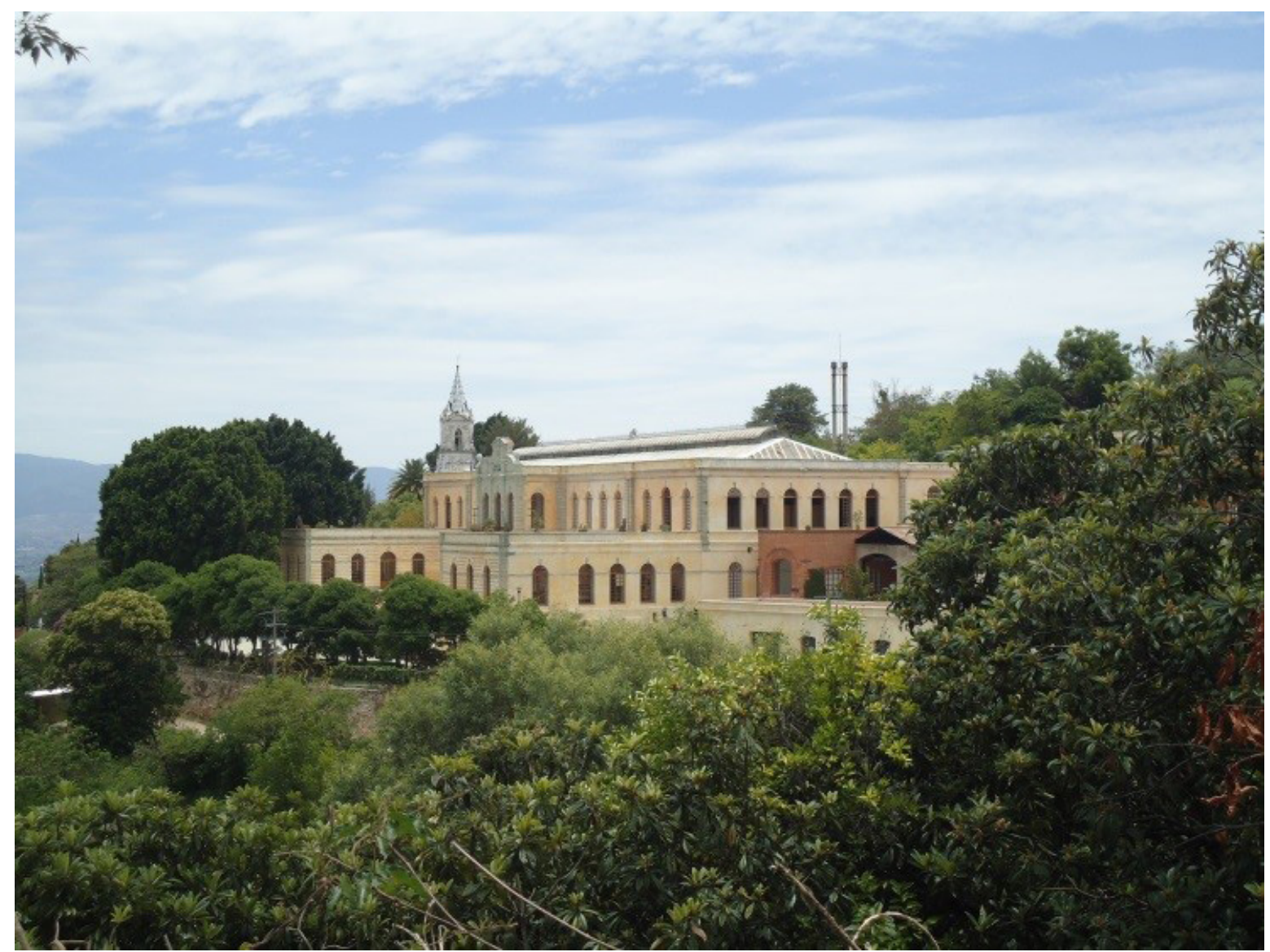

Imagen 5. Vista surestenoreste del conjunto fabril. Fuente: Archivo CAPUAO fundición, 46 en total, desplantadas desde una base cuadrada en forma de campana.

Esta columna, en su desarrollo vertical y encuentro con el sistema de cubierta, presenta una cabeza cónica que sostiene una placa cuadrada en una especie de capitel muy simplificado. Sobre esta columna se apoya sobre el eje transversal, el sistema de viguetas ( 23 en total), que a su vez sostienen el sistema de entrepiso a base de duelas de madera tratada, colocadas sobre el eje longitudinal (ver imagen 6).

La planta alta presenta una variante en su solución estructural. El sistema de cubierta sin apoyos internos privilegia el soporte en los muros perimetrales. La estructura de cubierta fue solucionada usando una esbelta armadura francesa, la cual está integrada por cerchas de hierro, colocadas sobre el eje transversal y separadas 3.5 metros entre sí (ver imagen 7). La cubierta realizada con láminas metálicas acanaladas de zinc tiene dos pendientes mayores hacia los muros longitudinales (norte-sur), y dos menores hacia los muros transversales (este-oeste). Al mismo tiempo, se integra en la cumbrera de cubierta un eficiente sistema de ventilación e iluminación a partir de otra cubierta curva y metálica, que se practica un metro más alta que las cubiertas principales, a lo largo de todo el eje longitudinal de la planta alta. Es importante resaltar que la cubierta integró un sistema pasivo de enfriamiento, llevando agua hasta la cumbrera para deslizarla por las láminas y bajar la temperatura exterior, y, por consiguiente, la in- 


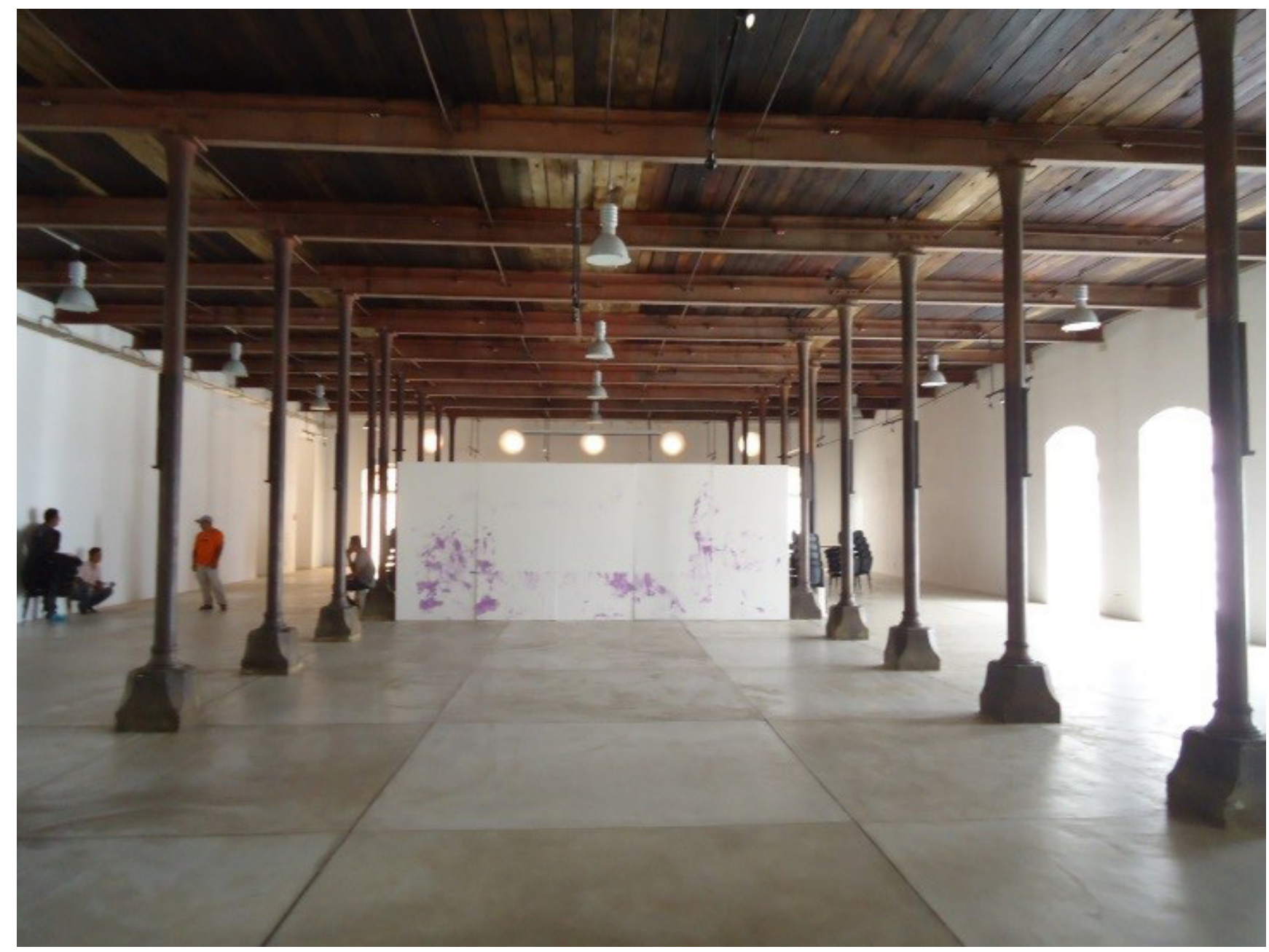

Imagen 6. Primer nivel de la planta de producción. Fuente: Archivo CAPUAO. 


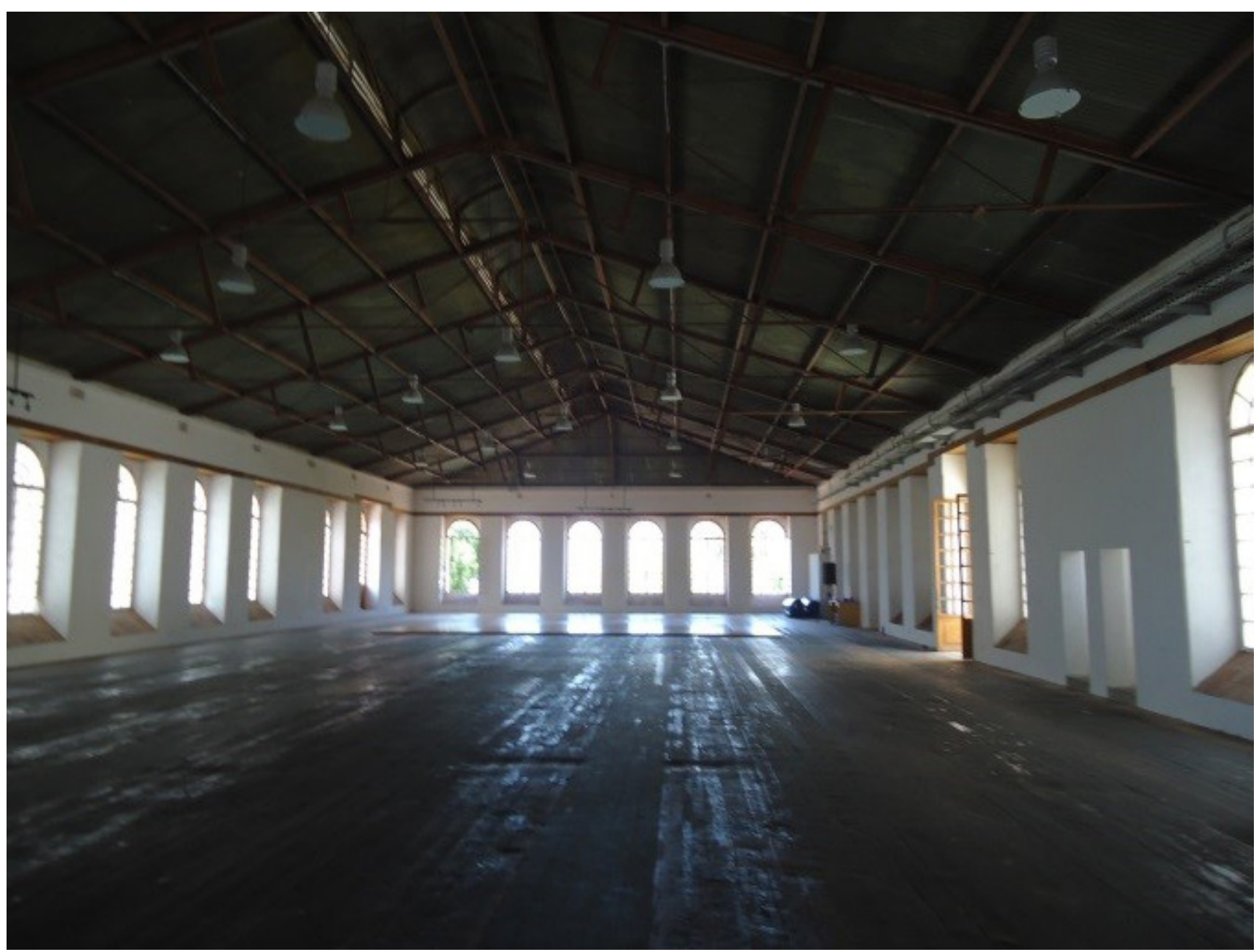

Imagen 7. Segundo nivel de la planta de producción. Fuente: Archivo CAPUAO. 
terior, ya que la jornada laboral demandó una permanencia prolongada de los trabajadores durante el día.

El funcionamiento de la planta de producción, como es deducible, estuvo regido por la masividad y concentración espacial de las áreas de hilado y tejido. Este espacio de dos plantas funcionales estuvo complementado, por ejemplo, en la planta baja del lado sur, por dos volúmenes ubicados en los extremos. En el primero, al este, funcionó la paquetería (ventas), y al oeste batientes donde se realizaba la limpieza del algodón. Al parecer la rampa ubicada en este espacio sirvió para llevar el material a la planta alta. En esta, las azoteas de los dos espacios (paquetería y batientes) se utilizaban como terrazas de descanso con una vista sur hacia el valle de Etla. Al centro de este lado sur, y franqueado por los dos volúmenes descritos, se edificó el acceso principal de la fábrica, descrito más adelante.

Así, también por el lado norte de la planta de producción, se encontraban dos espacios de estrechas dimensiones para el cordonero este y cordonero oeste, unidos entre sí por un ajustado patio longitudinal de aproximadamente 12 x 20 metros. El nivel de desplante de este patio estaba en una marcada diferencia con respecto al resto de espacios al norte, debido principalmente a los niveles topográficos utilizados en las plataformas. También en este patio se encontraba un básico núcleo sanitario para los trabajadores, repetido en la planta alta o de tejido.

En estos mismos espacios en la planta alta o de tejido funcionaron las urdidoras, y en el anexo a la urdidora del oeste se encontró el área de engomado, donde una vez que el tejido ingresaba, se enderezaba, planchaba, doblaba, enterciaba, prensaba y empaquetaba. Esta área de engomado funcionó con una caldera ubicada al exterior y al centro del eje transversal en el lado norte, la cual aún pervive, con sus dos chimeneas de asbesto de aproximadamente 12 metros de altura, las cuales se han convertido en el eje visual y punto de referencia en las actuales instalaciones y funcionamiento.

Hacia el este del volumen principal se encuentra localizado el núcleo de instalaciones o cuarto de máquinas, donde aún se conserva parte del generador que sustituyó al suministro de energía hidroeléctrica. Es un edificio construido con tabique rojo, originalmente cubierto por una bóveda de cañón corrido de arco rebajado, aún apreciada en su trazo, pero que fue sustituida años más tarde por una cubierta de lámina a dos pendientes. Delimitando esta zona de servicios e instalaciones, se ubicó el área de vivienda de los capataces. Fue semiprivada, porque contaba con un acceso independiente desde la calle, y comunicación directa con el edificio de producción. Su volumetría es afectada constantemente por el desplante en una topografía variable, lo que produce distintas alturas espaciales y formales con un lenguaje tradicional entre macizo y vano, cubiertas con sistema de vigas de madera y enladrillado.

En las plataformas cuatro y cinco, localizadas en el lado norte, y en una acotación superior frente al chalet del administrador, la planta de producción y las viviendas del personal o los capataces, se localizaron las calderas, con sus chimeneas o chacuacos —que también sirvieron de señal acústica para el inicio y final de la jornada labo- 
ral,$-{ }^{17}$ y dos zonas de vivienda — se dice para obreros-, escalonadas por la topografía y una diferencia de desplante de aproximadamente cuatro metros.

Así también se debe anotar la existencia, hacia el este, y separada de las viviendas del personal o los capataces, de una zona formada por el Molino de San Diego — actualmente perdido-, los posibles almacenes de materia prima y viviendas, las caballerizas y, muy importante señalar, la construcción de una escuela primaria para trabajadores

en Oaxaca, la escuela ayudó a la castellanización de los operarios, a quienes se les dificultaba la comunicación con los capataces. Esta desventaja era un elemento favorable a la producción, que alentaba la sumisión y la obediencia, puesto que los operarios actuaban de manera mecánica..$^{18}$

Por otro lado, también «en Vista Hermosa no faltaron las quejas de los trabajadores en el sentido de que, con la asistencia de los hijos de la familia Trápaga-Zorrilla a la escuela de la fábrica, los instructores hicieron odiosas distinciones entre los grupos de estudiantes». ${ }^{19}$

La enseñanza en este inicio del siglo xx fue una iniciativa de los empresarios, quienes buscaron homogeneizar el nivel educativo de la población con los estándares básicos europeos y, al mismo tiempo, formar en los trabajadores una conciencia social, para años más tarde despertar - sin ser este el objetivo- una conciencia política que desencadenaría en los conflictos con la fábrica.

\section{El volumen fabril}

La planta de producción, en conjunto con los espacios complementarios, presenta importantes características formales y volumétricas que, sin alejarse de la norma de la época, manifiestan su singularidad para este enclave rural. La masividad en el uso de la frontalidad es ostensible, así como el uso de la simetría geométrica y volumétrica es notorio. Esto se aprecia primero en el rastro del acceso principal - hoy desaparecido - sobre la calle José María Méndez, al sur del edificio. La fuerte diferencia de nivel entre calle y plataforma hace plausible la hipótesis sobre la existencia de una primera escalera, la cual comunicó directamente la calle con la plataforma de la planta de producción, para dominar en esta llegada la frontalidad del volumen. Sobre este eje llamado transversal de acceso, se construyeron tres elementos de la planta de producción para marcar esta jerarquía

17 El silbato de vapor de los chacuacos sonaba media hora antes a fin de avisar la hora de entrada. El sonido era tan potente que se escuchaba en otras poblaciones. Este llamado también solía hacerse con las campanas de la capilla o iglesia, la cual, al ser propiedad de la fábrica, se utilizaba cuando no había calderas funcionando. Velasco, op.cit., 371.

18 Ibídem, 355.

19 Ibídem, 356. 


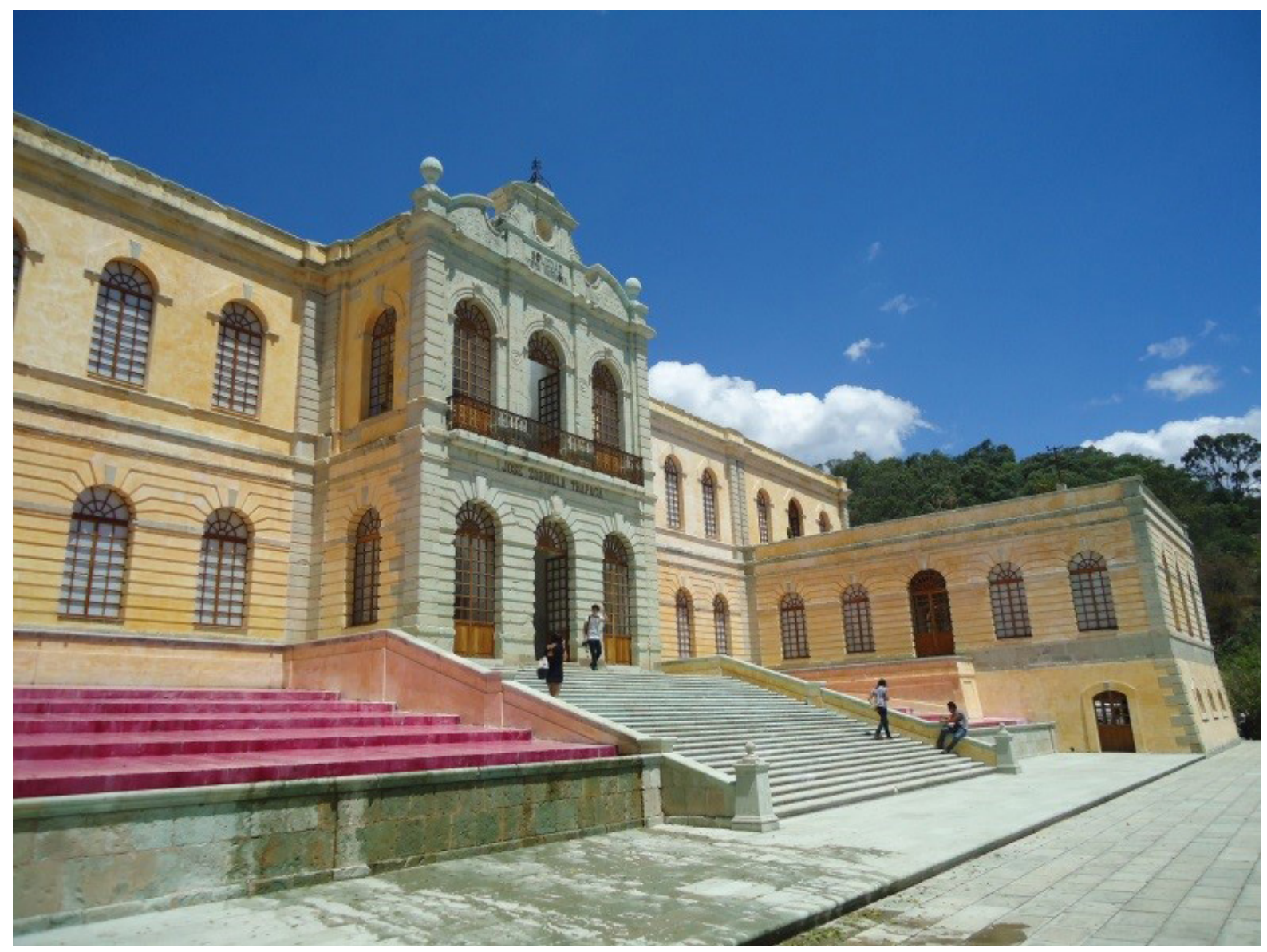

Imagen 8. Acceso sur del edificio fabril. Fuente: Archivo CAPUAO del acceso sur: la plaza; el dominante cuerpo de escaleras franqueadas por jardineras de generosas dimensiones, las cuales, en su nivel de llegada, enlazan con los volúmenes de paquetería y batientes, que también refuerzan la simetría del conjunto (ver imagen 8); y el tercer elemento (que se yergue al final de la escalera principal del acceso sur), el pabellón de acceso. Este volumen tiene unas dimensiones de $16 \times 32 \times 48$ pies, en una clara proporción 1:2:3. Por esta razón, se adosa al cuerpo de la planta de producción y está remarcado por el uso exclusivo de cantera verde; cornisas; pilastras; un acusado almohadillado - que también es usado en el volumen de la planta de producción-; y seis vanos (puertas-ventanas) al frente, generados por sus respectivos arcos de medio punto: tres para el nivel de acceso - el arco central incorpora grabada en la piedra clave el año de 1883 como inicio de operaciones-, y tres en la planta de tejido con balcones en cada uno de los vanos, pero integrados visualmente por el barandal continuo de herrería. El volumen termina integrando el motivo de los arcos con cuatro laterales: dos en los lados este y dos en el oeste.

Al llegar hacia el interior de la planta de producción se sube de distintas maneras el escalonamiento de las plataformas: la primera escalera va de la calle a la plaza, después se encuentra la monumental escalera de la fachada principal, la cual, después de ser traspasada, da al interior de este volumen que sirve como filtro-vestíbulo de acceso a la nave principal de producción. Un cuerpo de escaleras interiores permite el ingreso a la nave de hilado. Al mismo tiempo, una ornamentada escalera circular de fierro fundido se presenta como alter- 
nativa directa para subir a la nave de tejido, e inclusive, por el vestigio existente, comunicaba con la azotea de este edificio.

Esta secuencia espacial de escalonamiento es percibida sobre el eje transversal, no así sobre la percepción volumétrica exterior sobre el eje longitudinal, al contrario, la fuerte horizontalidad del conjunto oculta su integración topográfica a través de las plataformas descritas. En este sentido, los acabados son distintos. En planta baja un fuerte almohadillado, cornisas a nivel de entrepiso en toda la extensión y un acabado liso en planta alta, así como la cornisa de remate y su respectivo pretil de azotea, son suficientes para mitigar las alturas conseguidas en los desplantes hacia el norte y expresar en el sur la altura de dos niveles, salvando gradualmente por las plataformas una diferencia de 15 metros sobre el eje transversal.

El sistema de iluminación es logrado en la nave de hilado y tejido, a través de la perforación de los espesos muros perimetrales. Los vanos, con su carpintería de ventanas moduladas, son verticales - casi a dos terceras partes de la altura de cada piso-, terminando en arcos de medio punto. Para la planta baja o de hilado, por los niveles topográficos del desplante, en el lado norte, la iluminación no se resolvió adecuadamente, a diferencia de los lados sur, este y oeste. En este sentido, la ventilación cruzada es lograda en dos de sus lados en planta baja, y bien resuelta en planta alta, por no haber obstáculos para lograrla.

Para Israel Katzman, la tendencia que describe mejor la fábrica del siglo xix es la del utilitarismo, en la cual, la preeminencia de los elementos útiles para el funcionamiento y construcción está determinada por los criterios económicos y de ejecución constructiva en el menor costo, por los paradigmas del capital, costo y tiempo. Dice al respecto:

después de lo clásico y de los eclecticismos que llamamos integrado, francés y clasicista, el tipo de arquitectura más frecuente en el siglo XIX es el TRADICIONALISTA MUY SIMPLIFICADO, que en ciertas obras podríamos llamar utilitaristas con poco ornato. Aunque en muchos casos esta simplicidad es la consecuencia de las limitaciones económicas impuestas y en algunos géneros - como en la fábrica - fue porque se consideraba un tema indigno del arte, otras veces parece que existió realmente una voluntad de estética de simplificación. ${ }^{20}$

Pero en la mayoría de las fábricas del siglo xix, incluyendo la fábrica La Soledad, esta simplificación deja patentes las ambigüedades propias de la naciente modernidad, que no termina de separase de la tradición, pero incorpora temas de la nueva técnica. Si bien la zonificación general plantea a la fábrica como la nueva catedral del trabajo en el naciente siglo xx —como la definiría Walter Gropius en 1919-, a pesar de utilizar el esquema y motivos formales arquitectónicos del palacio barroco europeo, ${ }^{21}$ siendo por esto un neobarroco, la existen-

20 Katzman, Arquitectura del siglo XIX en México, Trillas, 180.

21 Espadas, «El Neobarroco del Palacio Socialista o Casa del Pueblo». 
cia de la zona religiosa expresa la omnipresencia del dominio socioeconómico que la iglesia aún mantenía en esas décadas. Esta ambigüedad entre tradición y modernidad es más clara entre la epidermis de la planta de producción y su sistema espacial interior: una arquitectura dura, de piedra, anclada en la tratadística clásica, pero que en su interior es de huesos estructurales, industriales, diáfana, oscura por el hierro como material dominante. Se observan dos tiempos en colisión: el de la tradición, estable, permanente y con cambios imperceptibles y el fugaz, vertiginoso y volátil de la primera modernidad.

\section{El deterioro de la fábrica y su restauración sociocultural}

Con el advenimiento de la Revolución Mexicana, las industrias del país entraron en un periodo de recesión de diversa casuística, desde la desmedida protección a los capitales extranjeros hasta la importación de productos estadounidenses y europeos en un mercado cada vez más competitivo. Aunado a este escenario posrevolucionario, las huelgas, quiebres financieros, cierres planificados y la incertidumbre de los trabajadores fueron incrementándose, la quema en Ixtlán de Juárez de la fábrica de Xía hizo que la situación fuera más vulnerable para la fábrica La Soledad, que seguramente estuvo resguardada por las fuerzas armadas, dado que en esta propiedad se ubicaba la planta hidroeléctrica de la que dependía el suministro de energía eléctrica para la ciudad de Oaxaca.

Al morir José Zorrilla, al parecer la fábrica fue arrendada, pero sometida a una gran presión por el pago de impuestos al gobierno en turno. Se decidió suspender las actividades productivas, con el enojo de los obreros, quienes constituyeron un sindicato para defender sus derechos laborales con el apoyo de otras organizaciones sindicales nacionales. En este escenario de conflicto laboral, los diarios fueron los portavoces de las dos partes para con la opinión pública empresarios y gobernantes-, sin embargo, el conflicto dejó de ser un tema del gobierno local, se dirimió a los propietarios en la Suprema Corte de Justicia de la Nación en 1922. Por esto y por una serie de acontecimientos legales de cierre sistemático, así como un retraso tecnológico en la maquinaria, que se volvía obsoleta sin renovación, la fábrica La Soledad entró en un periodo de crisis del cual no volvió a salir, con consecuencias socioeconómicas para la población y la arquitectura como testigos del deterioro que gradualmente fue acumulando en su fisonomía.

Después de décadas de conflicto obrero-patronal, entre 1960 y 1970, las fábricas de San José y La Soledad, fueron entregadas a los obreros

por la junta de Concilliación y Arbitraje por haberlas declarado en quiebra sus patrones. Los obreros trabajaron bien por algún tiempo, pero hubo dificultades entre copropietarios (aque- 
llos a quienes los patrones entregaron como pago de salarios las escrituras de la fábrica) y cooperativistas (nuevos empleados que fueron contratados por los copropietarios y con quienes formaron una cooperativa), cerrando sus puertas para siempre en $1989 .{ }^{22}$

\section{Una nueva oportunidad de uso cultural contemporáneo para la fábrica textil-CASA}

Frente a esta muerte anunciada del complejo industrial, y por consiguiente del entorno laboral, con su impacto socioeconómico, fue hasta el año 2000 que la fábrica fue comprada por el pintor Francisco Toledo y el Gobierno del estado, representado por el Lic. José Murat Casab (1998-2004), quienes en proporción 40\% - 60 \% respectivamente realizaron el pago del inmueble con el objetivo de iniciar su restauración para convertirlo en archivo del estado. A pesar del desacuerdo entre ambos actores, finalmente, en ese mismo año, inició su restauración para convertirse en el primer centro de las artes ecológico de Latinoamérica, orientado a la formación, creación y experiencia artística con el nombre de Centro de las Artes de San Agustín (CASA). Este centro abrió sus puertas el 21 de marzo de 2006,

Imagen 9. Galería de exposición en planta baja. Fuente: Archivo CAPUAO. financiado por el Consejo Nacional para la Cultura y las Artes (Conaculta), el Centro Nacional de las Artes (Cenart) y el Gobierno del

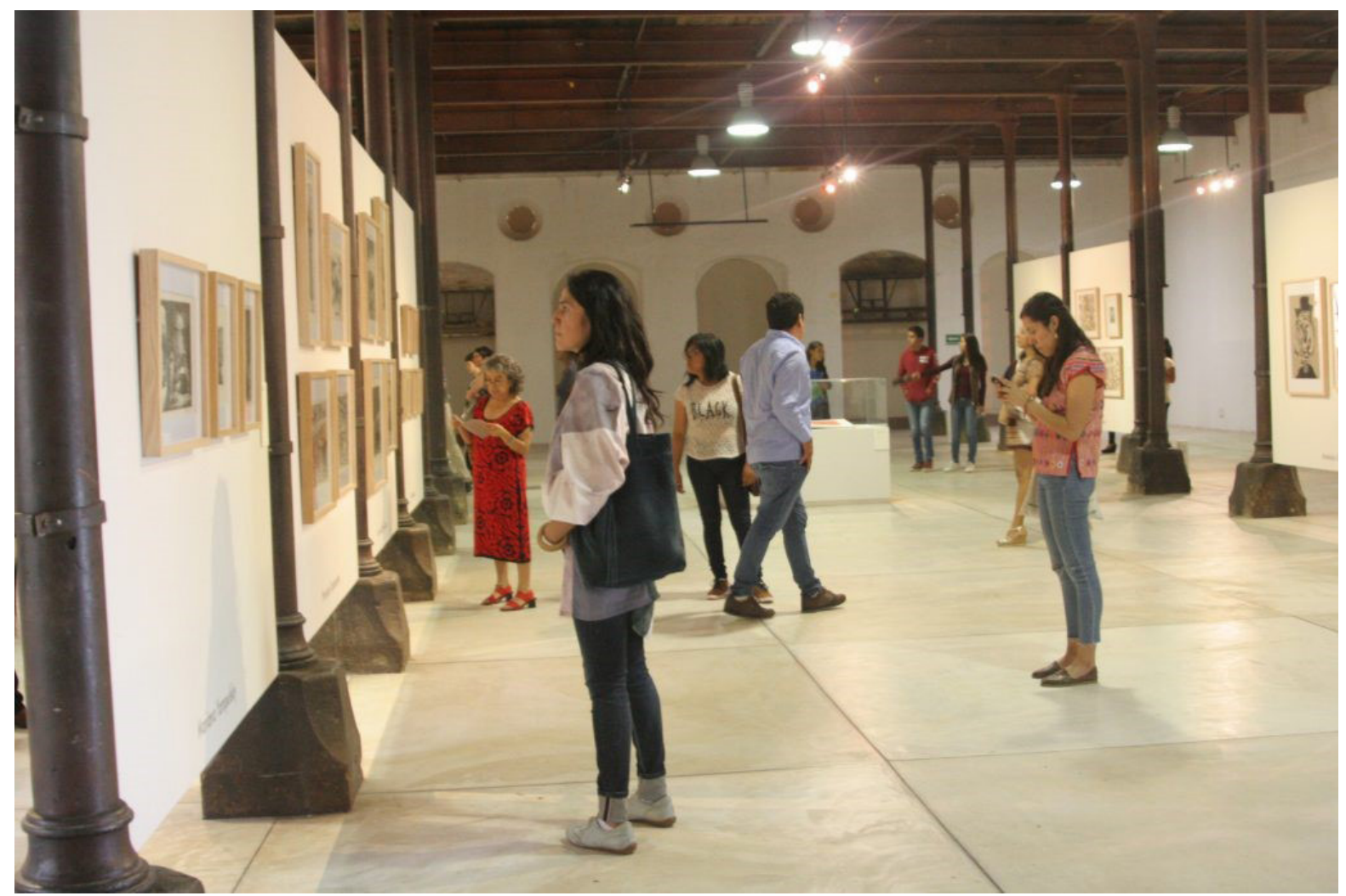

22 Velasco, op.cit., 463. 


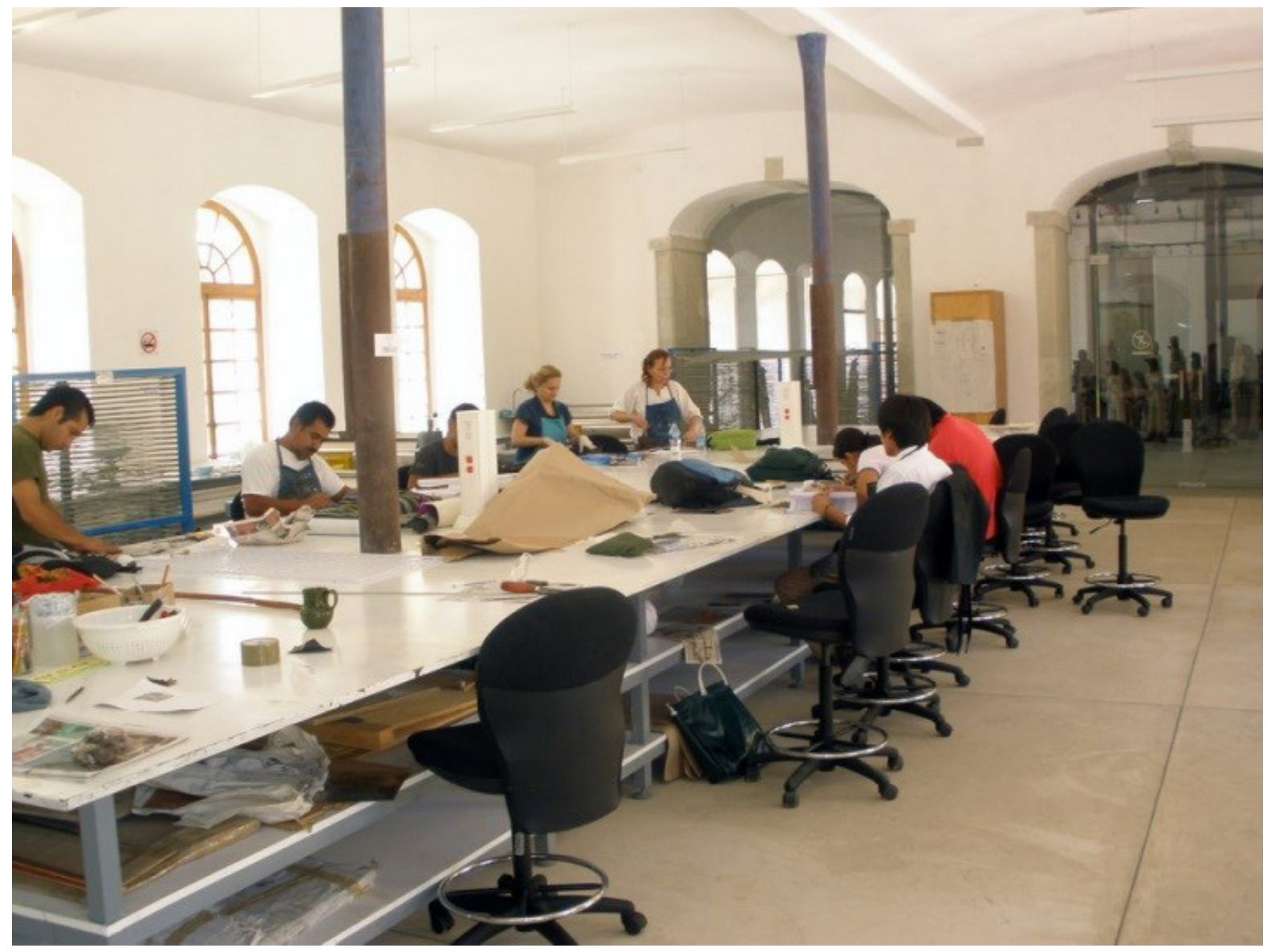

Imagen 10. Talleres de gráfica en planta baja. Fuente: Archivo CAPUAO.
Estado de Oaxaca, a través de la Secretaría de Cultura, así como por fundaciones como Alfredo Harp Helú y Amigos del Instituto de Artes Gráficas de Oaxaca (IAgo).

La restauración del edificio estuvo a cargo de la Arq. Claudina López, quien vio claramente la vocación ecológica del edificio, cuyo punto de partida fue que la antigua fábrica trabajaba con agua, y por ello consideró el agua como elemento importante en esta restauración. Es por ello que se observan varios espejos de agua en el edificio restaurado, por ejemplo, uno en la entrada del CASA, frente al templo neogótico y otro que rodea la caldera que se encuentra en la parte trasera del edificio principal, donde se construyó un núcleo sanitario para el nuevo uso de las instalaciones. El agua también está presente en las dos fuentes que enmarcan el acceso principal del espacio fabril. El agua de estas fuentes es de color rojo, cuya tintura es de cochinilla, lo cual habla de la temática textil. Por otro lado, desde la cuestión técnica funcional del edificio, se utiliza el agua para enfriar el techo con un sistema de tuberías que hace rememorar la lluvia. Toda el agua que se ocupa para estos espacios arquitectónicos se vuelve a recolectar y se integra nuevamente al recorrido natural.

En los dos niveles de lo que fue la nave industrial de la fábrica textil se habilitaron dos grandes galerías. La planta baja ha sido destinada para exposiciones de fotografía, gráfica, cerámica y carteles (ver imagen 9). La parte superior de esta nave está destinada para conciertos, funciones de teatro de marionetas, salas de conferencias y exposiciones de los alumnos. El complejo arquitectónico también incluye un laboratorio de fotografía ecológico, que es ecológico dado que 
el agua que se requiere para el revelado de las fotografías se somete a un proceso de filtración, en el que, por medio de estanques, los cuales son los techos de las aulas, se va purificando esta agua.

El recinto cuenta con taller no tóxico de gráfica tradicional, equipado con electro etch ${ }^{23} \mathrm{y}$ con un taller de gráfica digital (ver imagen 10). También cuenta con espacios como el laboratorio de videodanza y coreografía expandida, la sala audiovisual, cuatro aulas, una sala de cine, el acervo de cine El Pochote y seis habitaciones dedicadas al alojamiento de artistas residentes. Entre las actividades que ofrece hay cursos, talleres, seminarios y diplomados en diferentes áreas artísticas como dirección y producción escenográfica, composición musical, curaduría y gestión de exposiciones, al igual que conferencias, cine, teatro, exposiciones de artes plásticas, presentaciones de libros, performances, presentaciones de danza, conciertos, producción de obras de artistas y producción editorial, entre otras. Las actividades del centro priorizan la enseñanza y producción artística orientada a temas ecológicos y de atención a la comunidad. Es considerado el primer centro de arte ecológico de Latinoamérica por sus muros renovados y sus galerones limpios, donde se expone lo mejor del arte moderno local, nacional e internacional.

\section{Reflexiones finales}

En un enclave vernáculo, al norte de la capital de Oaxaca, se ha construido a lo largo del siglo xx una historia en la cual el paisaje natural fue determinante para convertir este enclave en paisaje cultural. Una fábrica de hilados y tejidos se asentó a finales del siglo XIX en San Agustín Vista Hermosa, Etla, y con la arquitectura construida bajo los parámetros del eclecticismo decimonónico, con aura de palacio neobarroco y una clara ambigüedad, así como conflicto entre tradición y modernidad, este entorno vernáculo adquirió notoriedad económica para el estado. Una arquitectura monumental erigida para la producción textil, representativa del auge industrial en el periodo del Porfirismo, años más tarde también ejemplificó las contradicciones entre el desarrollo del capital y los trabajadores, desequilibrio que desencadenó su cierre, desmantelamiento y rápido deterioro. Esta fábrica y su impronta socio-arquitectónica quedaron por décadas en el olvido, y se convirtió en parte de un paisaje vernáculo en conflicto. Sin embargo, a principios del siglo xxI, la fábrica La Soledad, después de un largo proceso de restauración arquitectónica con enfoque contemporáneo, logró también restaurar su importancia social y cultural para el sitio, ya que, al convertirse en el Centro de las Artes de San Agustín, pionero en Latinoamérica como centro de arte ecológico, detonó un enclave sociocultural y académico centrado en el desarrollo comunitario, de ahí su importancia en la actualidad para Oaxaca.

23 Es un proceso de grabado de metales que implica el uso de una solución de electrolito, un ánodo y un cátodo. Para reducir los efectos electroquímicos no deseados, el ánodo y el cátodo deben ser del mismo metal. 


\section{Bibliografía}

Ábalos, I. Atlas pintoresco. Vol. 1: el observatorio. Barcelona, España: Gustavo Gili, 2005.

Dixon J. Gardens and Pinturesque. Studies in the History of Lanscape Architecture. Cambridge: MIT Press, 1994.

Espadas Medina, Aercel. «El Neobarroco del Palacio Socialista o Casa del Pueblo». Revista Arquitectura de Yucatán, Cuadernos 6, (1993): 80.

Lira Vásquez, Carlos. Arquitectura y sociedad. Oaxaca rumbo a la modernidad. México: UAM, 2008.

Martínez Medina, Héctor, y Ruiz Cervantes, Francisco. «La ciudad de Oaxaca. de la independencia a los inicios del periodo posrevolucionario». En 474 años de la fundación de Oaxaca, editado por Sebastián van Doesburg, 7-95. México: Exima, 2007.

Martínez Sánchez, Félix A., Hinojosa de la Garza, Karla María, y Navarrete, Armando Alonso (coord.). Arte, Historia y Cultura. Nuevas aproximaciones al conocimiento del paisaje. Ciudad de MéxiCO: UAM, 2017.

Ramírez, G. Las casas patio de Mies van der Rohe: un jardín de la modernidad. Una lectura desde el concepto de pluralidad y desde la tercera naturaleza. Revista de Arq., Num. 19. Arquitectura y Antropología (2016): 140-145.

Vargas R. Historia de la Arquitectura y el Urbanismo Mexicanos, volumen III. El México Independiente, tomo II. Afirmación del nacionalismo y la Modernidad. Ciudad de México: UNAM, FCE, 1998

Velasco Rodríguez, Griselle. Capitalismo y modernización en Oaxaca: la industria textil durante la Reforma y el Porfiriato. México: Politécnico Nacional, 2011.

\section{Créditos de imágenes}

Todas las imágenes pertenecen al archivo del Cuerpo Académico Patrimonio Urbano-arquitectónico en Oaxaca, siglos XVI-XXI, Facultad de Arquitectura CU, Universidad Autónoma Benito Juárez de Oaxaca, a excepción de la imagen 2, que fue proporcionada por la Arq. Claudina López quien fue la encargada de la restauración e intervención contemporánea en la exfábrica de hilados y tejidos La Soledad. 